\title{
Psychometric Properties of Smartphone Addiction Inventory (SPAI) in Russian Context
}

\author{
Almira R. Bayanova \\ Kazan (Volga Region) Federal University, Kazan, Russia \\ ORCID: 0000-0003-2311-3924 \\ Alexey A. Chistyakov \\ The State University of Management, Moscow, Russia \\ ORCID: 0000-0003-4266-2515 \\ Maria O. Timofeeva
}

I. M. Sechenov First Moscow State Medical University (Sechenov University), Moscow, Russia

ORCID: 0000-0001-7222-7042

Vladimir V. Nasonkin

Peoples' Friendship University of Russia (RUDN-University), Moscow, Russia

ORCID: 0000-0002-4467-7473

Tatiana I. Shulga

Moscow State Regional University, Moscow, Russia

ORCID: 0000-0002-3584-6087

Vitaly F. Vasyukov

Moscow State Institute of International Relations (MGIMO University), Moscow, Russia

Orlovsky Law Institute of the Ministry of Internal Affairs of the Russian Federation named after V. V.

Lukyanov, Orel, Russia

ORCID: 0000-0003-0743-5616

Received: 16 Nov 2021

Accepted: 28 Dec 2021

\begin{abstract}
Smartphones facilitate communication, education, information, and entertainment through a diverse array of mobile applications. Excessive smartphone use has become a significant societal issue. The research community has explored both the positive and negative consequences of mobile phone use. The phrase "problematic smartphone use" refers to an excessive pattern of smartphone use that may have negative consequences. Smartphone addiction may present with symptoms that are unique from Internet addiction. Severe sadness, anxiety, and tension are all associated with problematic smartphone use. Numerous negative consequences are discussed, including mental health problems, diminished physical fitness, and poor academic achievement. According to the findings of the literature analysis, there is no inventory that evaluates smartphone addiction in the context of Russia. The goal of this study is to examine the psychometric characteristics of the smartphone addiction inventory (SPAI) in a Russian context. Several Russian Federation universities performed the study during the autumn semester of the 2020-2021 academic year. To enhance the inventory, Exploratory Factor Analysis (EFA) and Confirmatory Factor Analysis (CFA) were utilized on 209 students. As a result, research on the validity and reliability of the Smartphone Addiction Inventory were done in the Russian setting. The research revealed a brief inventory of 14 items and three factors (functional impairment, anxiety, and compulsive behavior).
\end{abstract}

Keywords: smartphone addiction inventory, psychometric properties, exploratory factor analysis (EFA), confirmatory factor analysis (CFA), university students 


\section{INTRODUCTION}

Increasingly common in everyday life, smartphones provide a wide range of mobile applications for communication, education, information and entertainment. While it is stated that 6.055 billion smartphones are used worldwide in 2020, this number is estimated to be 6.378 billion in 2021 and 7.516 billion in 2026 (O'Dea, 2021). With the rising popularity of smartphones, excessive smartphone use has emerged as a serious societal concern (Lin et al., 2014). However, it is not only possession of electronic equipment that is creating worry in the domains of psychology and cognition. Rather than that, it is the potential for dysfunction linked with smartphone usage that is prompting academics to emphasize the critical nature of studying the habit (Harris et al., 2020).

According to Gutierrez et al. (2016), the most major corpus of behavioral addictions today - the Internet, videogames, and mobile phones - are the subject of a growing number of research. In the past, Internet usage might manifest as a worldwide addiction or as involvement with addictive material and behaviors. Young (2009) looked at five main types of Internet addiction: (1) the computer itself, (2) the quest for information, (3) interaction compulsions, such as engagement with the web through online games, shopping, and so on, (4) cybersexuality, and (5) cybercontacts. At this point, technological addiction becomes apparent. Technology addiction is described as a compulsive and regular manner of using technology to avoid dealing with life's various difficulties (Agarwal \& Kar, 2015). Thus, Lin et al. (20214) suggest that "Smartphone addiction" might be regarded a type of technology addiction.

As a result of this explosion in mobile phone use, research has lately exploded to examine both the beneficial and negative repercussions of mobile phone use (Billieux et al., 2015). The usage of a mobile phone entails optimizing communication between persons and systems. Additionally, mobile phone technology facilitated the development and validation of a diverse range of health-related and behavior change interventions and applications that aide in the management of such activities as weight management, smoking cessation, physical activity promotion, and chronic disease management (Akhmadieva et al., 2021; Anstey Watkins et al., 2018; Fjeldsoe et al., 2009; Marcolino et al., 2018).

There have been a variety of negative outcomes associated with mobile phone use, particularly excessive use, including (but not limited to) self-reported dependence and addiction-like symptoms, sleep disruption, financial difficulties, dangerous use (phoning while driving), prohibited use (phoning in prohibited areas), and mobile phone-based aggressive behaviors (e.g., cyberbullying) (Billieux et al., 2015; Chhabra et al., 2019; Oviedo-Trespalacios et al., 2017; Thomée et al., 2011).

According to American Society of Addiction Medicine (ASAM)

"Addiction is a treatable, chronic medical disease involving complex interactions among
brain circuits, genetics, the environment, and an individual's life experiences. People with
addiction use substances or engage in behaviors that become compulsive and often
continue despite harmful consequences. Prevention efforts and treatment approaches
for addiction are generally as successful as those for other chronic diseases." (ASAM,
2019).

For many individuals, the term "addiction" connotes the use of narcotics. As a result, it's somewhat unexpected that the majority of official definitions focus on drug intake. Despite these criteria, there is a growing consensus that a variety of behaviors, including several that do not entail the consumption of a drug, are potentially addictive. These include gambling, binge eating, sex, exercise, videogame activity, romance, Internet usage, and work (Griffiths, 2005). According to Pavia et al. (2016), the research has not reached a consensus definition of smartphone addiction due to the existence of a broad variety of pattern symptoms and indications that cannot be properly classified as indicators of addiction.

Research has shown that problematic smartphone use is related to impulsivity (Contractor et al., 2017; DeSola et al., 2017; Harris et al., 2020; Horvath et al., 2020; Tugun et al., 2020), impaired attention (Harris et al., 2020; Rezaee \& Pedret, 2018; Roberts et al., 2015), and compromised inhibitory control (Chen et al., 2016; 
Harris et al., 2020; Vezzoli et al., 2021).In recent years, academics and public health practitioners have focused more emphasis on problematic smartphone use such as smartphone addiction and nomophobia (fear of being detached from mobile phone connectivity). According to Awofala (2020), nomophobia is one of the predictive variables of smartphone addiction. However, given the idea of problematic smartphone use's relatively recent development as a research subject, definitions of the term are continually developing. Problematic smartphone use is a general term that refers to an obsessive habit of smartphone use that might have negative implications that impede the user's everyday functioning. Compulsive usage is a term that refers to an uncontrollable overuse of a smartphone that is characterized by maladaptive reliance and a proclivity to use it without being removed from it (Busch \& McCarthy, 2021).

It is important to measure the prevalence of many addictive behaviors arising from digital tools among young people and adolescents. Such behaviors need to be addressed from both a psychological and a health point of view. For example; the research examined and assessed how changes in family structure affect online gaming addiction and delinquency in children in their vulnerable adolescence period. It is found that a considerable cause-and-effect link between juvenile delinquency and online gaming addiction (Choi et al., 2018). At the same time, it has been determined that addiction types such as internet addiction are also associated with cyberbullying (Mikhaylovsky et al., 2019). There is a relationship between addiction and misbehavior. In other words, addiction affects both themselves and the people around them.

Recent statistics on smartphone use indicate that only a tiny percentage of users exhibit addictive-like symptoms (Billieux et al., 2015; Elhai et al., 2017). Problematic smartphone use is connected with depression severity, anxiety, and stress (Arrivillaga et al., 2020; Elhai et al., 2017; Huckins et al., 2020). According to Mitchell and Hussain (2018), predictors of problematic smartphone use are impulsiveness, age, excessive reassurance seeking, and depression. There are no differences in terms of gender and extraversion personality type.

Although cellphones provide several benefits, researchers have explored various negative repercussions, including mental health difficulties (Bauer et al., 2020; Elhai et al., 2017; Thomée et al., 2011), decreased physical fitness (Lepp et al., 2014; Stanislaus et al., 2020), and decreased academic performance (Cha \& Seo, 2018; Felisoni \& Godoi, 2018; Lepp et al., 2014).

The symptoms of smartphone addiction may be distinct from those of Internet addiction. Lin et al. (2014) proved through exploratory factor analysis that smartphone addiction shares significant characteristics with DSM-5 substance-related disorders, including the following four major factors: obsessive behavior, functional impairment, withdrawal, and tolerance. In another study (Pavia et al., 2016), factors were named as "Time Spent", "Compulsiveness", "Daily Life Interference", "Craving", "Sleep Disorder".

Psychometric properties of smartphone addiction inventories were measured in different country contexts (Ching et al., 2015; Lopez-Fernandez, 2017; Pavia et al., 2016). In the literature review, no inventory was found that measures smartphone addiction in the context of Russia. It is aimed to contribute to the literature and to conduct a validity and reliability study of the inventory that can determine the prevalence of smartphone addiction among university students.

\section{METHODS}

The objective of this study is to determine the psychometric properties of smartphone addiction inventory (SPAI) in the Russian context. The study was carried out in the fall semester of the 2020-2021 academic year in the following Russian universities: Kazan Federal University, The State University of Management, Sechenov University, RUDN-University, Moscow State Regional University, and MGIMO University.

\section{Sample}

The sample group was selected to be university students who agreed to take part in the study. Researchers used convenience sampling technique in the sample determination process. The announcements were made by the researchers from the participating institutions. Participation in the study was entirely voluntary, and 
no compensation was offered. The sample is made up of 209 students, and $74 \%$ of the group consists of females and $26 \%$ of males who came from different grade.

\section{Inventory Items and Determination of Factors}

Inventory items (Appendix 1) were taken from the study by Lin et al. (2014). The inventory comprised 26 items that were originally categorized into four dimensions: functional impairment ( 8 items), withdrawal ( 6 items), compulsive behavior ( 9 items), and tolerance ( 3 items). In order to determine initial psychometric properties, EFA was conducted with a study group of 283 university students. As a result, it was found that the Cronbach's alpha for the overall scale was 0.94 , and that it was $0.87,0.88,0.81$, and 0.72 for the four variables, which were categorized as "compulsive behavior," "functional impairment," "withdrawal," and "tolerance," respectively. Four factors with eigenvalues greater than one were identified, and combined they explained 57.28 percent of the total variance (Lin et al., 2014).

Prior to undertaking factor analysis, the researchers determined if the obtained data were factorable; this was accomplished to determine whether the data obtained was sufficient to generate a series of factors. Williams et al (2010) advice using Kaiser-Mayer-Olkin (KMO) Sampling Adequacy Measurement and Bartlett Sphericity Test in order to determine factorability. KMO index is between 0 to 1 . A KMO index greater than 0.50 indicates factor analysis (Williams et al., 2010; Yong \& Pearce, 2013). Additionally, Bartlett's Test of Sphericity assures that variables and factors do not overlap (Hair et al., 2014; Yates, 1987) and should yield a significant level of p 0.5 to permit factorial analysis (Williams et al., 2010; Yong \& Pearce, 2013).

Exploratory Factor Analysis (EFA) and Confirmatory Factor Analysis (CFA) were employed to improve the inventory's overall quality. EFA is accepted in multivariate statistical method (Edwards \& Bagozzi, 2000; Watkins, 2018; Yates, 1987). Rotation approaches are used to obtain stronger structures in EFA. In this study, Varimax with Kaiser normalization was employed as a factor rotation approach in EFA (Hayton et al., 2004; Williams et al., 2010). The method of parallel analysis was used to identify the number of factors to be considered. In a parallel analysis, we evaluated real eigenvalues versus eigenvalues in a random order to see which was more accurate. In cases where real eigenvalues outnumber random ordered eigenvalues, factors are retained (Hayton et al., 2004; Williams et al., 2010). Additionally, the item is removed if it (a) loaded on multiple factors and the difference between the two loading factors is less than 0.1 , or (b) achieved a factor load less than 0.4 (Deng et al., 2017).

CFA is used to enhance items during inventory construction and validation by evaluating the nature and linkages of structures. Because the structural model is developed using CFA, a conclusive hypothesis regarding the instances analyzed may be produced (Jackson et al., 2009). To evaluate model fit, there is a need to analyze indices such as the chi-square goodness, Root Mean Squared Error of Approximation (RMSEA), Standardized Root Mean Square Residual (SRMR), Comparative Fit Index (CFI), and Tucker-Lewis index (TLI) (Yu, 2002).

\section{Reliability Calculations}

Cronbach alpha coefficient analysis was used to assess the newly designed tool's reliability. Alpha coefficient should be greater than 0.70 (Kline, 2005) and not greater than 0.94 for perfect reliability (Fraenkel et al., 2012; Taber, 2018). Additionally, we calculated composite reliability.

\section{Data Analyses}

Jamovi (The Jamovi Project, 2021) software was utilized in the study for EFA, CFA, and inferential analysis during the scale's psychometric assessments. It is stated that Jamovi is an open-source, free software package for performing basic statistical calculations. 0.05 was used as the statistical significance level. The measurement has a normal distribution (Shapiro-Wilk $W=0.99 p(0.178)>0.5$, Skewness $=0.168$, Kurtosis $=-$ $0.406)$ and have not outliers $(-2.09<z<2.82$, no outlier sign in boxplot). 
Table 1. Initial factor loading

\begin{tabular}{|c|c|c|c|}
\hline & Factor 1 & Factor 2 & Uniqueness \\
\hline Item 1 & 0.632 & 0.487 & 0.337 \\
\hline Item 2 & 0.614 & 0.507 & 0.365 \\
\hline Item 3 & 0.604 & 0.432 & 0.441 \\
\hline Item 4 & 0.678 & & 0.264 \\
\hline Item 5 & 0.594 & & 0.555 \\
\hline Item 6 & 0.680 & & 0.526 \\
\hline Item 7 & 0.615 & & 0.572 \\
\hline Item 8 & 0.505 & & 0.687 \\
\hline Item 9 & 0.572 & & 0.671 \\
\hline Item 10 & 0.627 & & 0.524 \\
\hline Item 11 & 0.668 & & 0.548 \\
\hline Item 12 & 0.580 & & 0.588 \\
\hline Item 13 & 0.595 & & 0.601 \\
\hline Item 14 & 0.527 & & 0.719 \\
\hline Item 15 & & & 0.771 \\
\hline Item 16 & 0.693 & & 0.507 \\
\hline Item 17 & 0.562 & & 0.652 \\
\hline Item 18 & 0.578 & & 0.599 \\
\hline Item 19 & 0.750 & & 0.429 \\
\hline Item 20 & 0.572 & & 0.627 \\
\hline Item 21 & & & 0.829 \\
\hline Item 22 & 0.677 & & 0.482 \\
\hline Item 23 & 0.708 & & 0.411 \\
\hline Item 24 & 0.673 & & 0.446 \\
\hline Item 25 & 0.690 & & 0.511 \\
\hline Item 26 & 0.701 & & 0.445 \\
\hline
\end{tabular}

\section{RESULTS}

First of all, exploratory factor analysis and then the results obtained will be confirmed by confirmatory factor analysis. Then, reliabilities' results will be shared.

\section{Exploratory Factor Analysis Result}

According to the results of the Bartlett test $\left(\chi^{2}=2611, d f=325, p<0.001\right)$ and the KMO test $(0.929)$, the study data can be used for factor analysis. Primarily, EFA was applied with no rotation. Loading factors are presented in Table 1.

The rotation method was applied to generate a stronger and more organized structure. The Varimax rotation has been applied. The loading factor was set at 0.4 as the cutoff value.

According to the results of parallel analyses (Figure 1), two factors have been identified. The initial eigenvalues of the first two components $(9.68$ and 1.11,) are greater than the eigenvalues obtained from simulation. Moreover, as can be seen in the Scree plot, the initial eigenvalues in the first two factors are higher than the values obtained by randomly simulating the first two factors. Items with loading values less than 0.4 were deleted and loaded on multiple factors, then the analysis was repeated. As a consequence, only 14 things remained following the removal of the items $5,6,7,9,12,14,15,17,19,20,21$, and 22 from the list of possible items. 


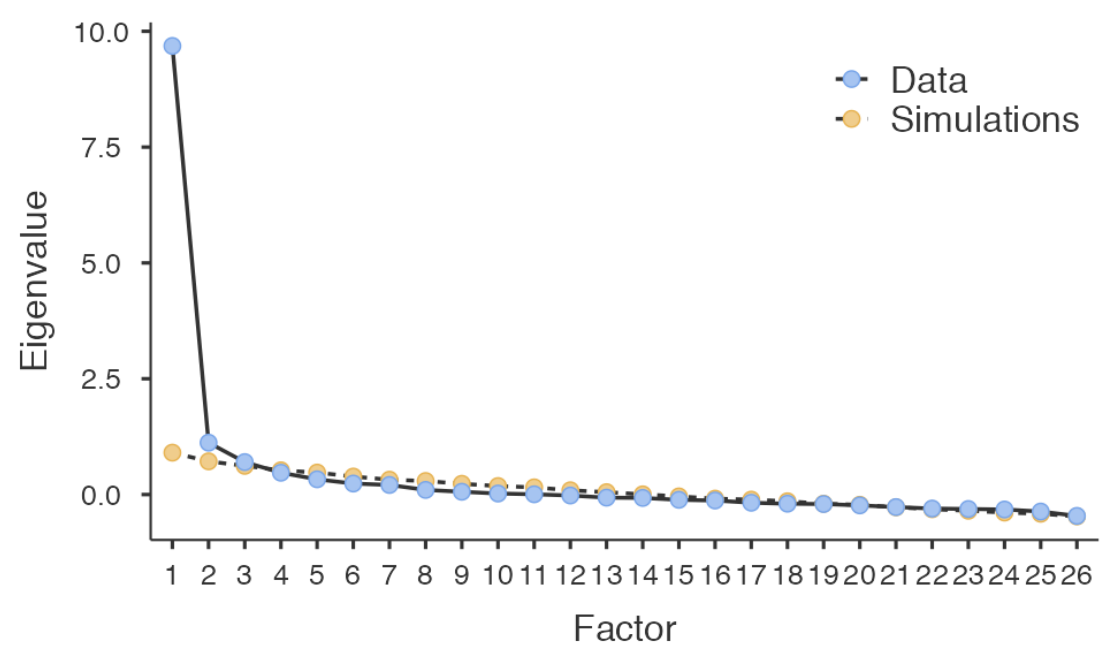

Figure 1. First solution for scree plot

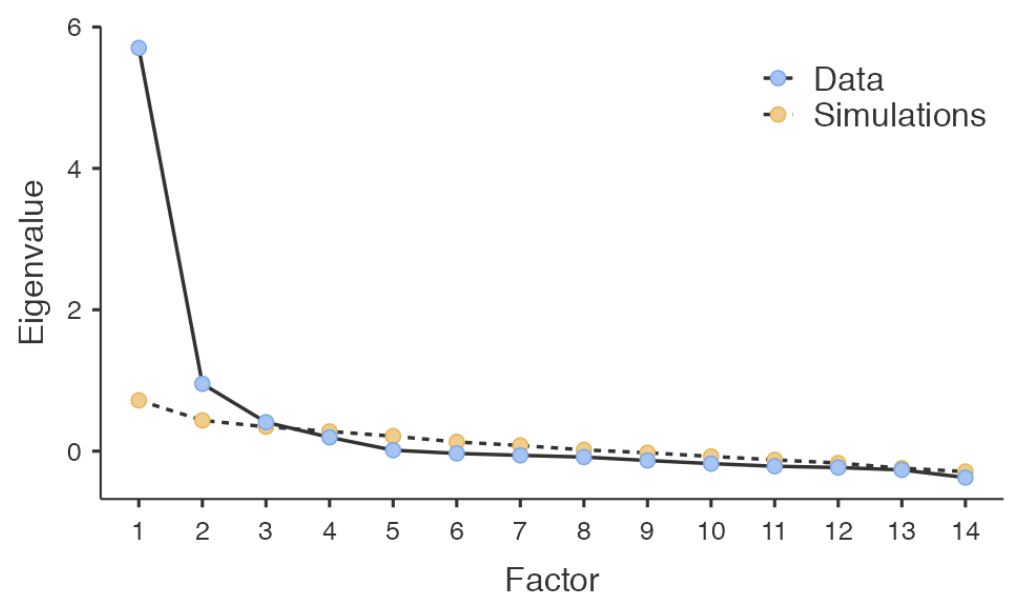

Figure 2. Final Solution of Scree Plot

Table 2. Final version factor loading

\begin{tabular}{lc}
\hline Items & Factor 1 Factor 2 Factor 3 \\
\hline I make it a habit to use smartphone and the sleep quality and total sleep time decreased. & 0.759 \\
I feel tired on daytime due to late-night use of smartphone. & 0.743 \\
I need to spend an increasing amount of time on smartphone to achieve same satisfaction as before. & 0.601 \\
I cannot have meal without smartphone use. & 0.595 \\
(My recreational activities are reduced due to smartphone use. & 0.516 \\
I have slept less than 4 h due to using smartphone more than once. & 0.511 \\
I feel aches and soreness in the back or eye discomforts due to excessive smartphone use. & 0.497 \\
I was told more than once that I spent too much time on smartphone. & 0.817 \\
I feel uneasy once I stop smartphone for a certain period of time & 0.755 \\
I find that I have been hooking on smartphone longer and longer. & 0.676 \\
I feel restless and irritable when the smartphone is unavailable. & 0.577 \\
I feel missing something after stopping smartphone for a certain period of time. & 0.646 \\
I feel distressed or down once I cease using smartphone for a certain period of time. & 0.628 \\
I fail to control the impulse to use smartphone. & 0.498 \\
\hline
\end{tabular}

KMO (0.907) and Bartlett's test $\left(\chi^{2}=1362, \mathrm{df}=91, \mathrm{p}<0.001\right)$ were calculated in the second analysis. They also are on a significant level. So, the data is useable for factor analysis.

Three variables were identified as a consequence of the parallel analysis. As seen in Figure 2, the initial eigenvalues for the first three components are bigger than the randomly produced simulation values. All items were gathered based on three factors. The factors and load values are as specified in Table $\mathbf{2}$. 
Table 3. The variances and total variances of the factors

\begin{tabular}{lccc}
\hline Factor & SS loadings & \% of variance & Cumulative \% \\
\hline Functional impairment & 3.15 & 22.5 & 22.5 \\
Anxiety & 2.67 & 19.0 & 41.5 \\
Compulsive behavior & 1.73 & 12.3 & 53.9 \\
\hline
\end{tabular}

Table 4. Fit indices for the initial model and final model

\begin{tabular}{lccccccc}
\hline & \multicolumn{1}{c}{} & \multicolumn{3}{c}{ RMSEA $90 \% \mathrm{Cl}$} \\
\hline Cut-off criteria & $\leq 2$ : good & $>0.90$ & $>0.90$ & $<0.08$ & $<0.05$ & Low & High \\
\hline Initial model & $154 / 74=2.08$ & 0.939 & 0.925 & 0.0507 & 0.0719 & 0.0558 & 0.0879 \\
Final model & $107 / 71=1.51$ & 0.972 & 0.965 & 0.0473 & 0.0495 & 0.0289 & 0.0679
\end{tabular}

Note: Chi-square goodness $\left(\chi^{2}\right)$, Degree of freedom(df), Comparative fit index (CFI), Tucker-Lewis index (TLI), Standardized root mean square residual (SRMR), Root mean squared error of approximation (RMSEA).

All factor loadings vary between +0.497 and +0.759 . In the factor I, there are 7 items. When the seven items listed above are taken into consideration, it will become clear that the items are connected to the impairment of the individual's quality of life. So, the first factor may be called as "Functional impairment". Second factor has 4 items. They are mostly related to an emotional issue. So, it may be called "Anxiety". They are mostly concerned with self-control. It might be referred to as "Compulsive behavior".

When factor structures such as those in Table 3 are examined, the scale of three factors and 14 items accounts for 53.9 percent of the total variance. These components provide a variety of topologies based on the correlation calculation between them. Correlation coefficients of $r=0.00$ are not statistically significant. As a result, "functional impairment," "anxiety," and "compulsive behavior" all refer to distinct structural components.

\section{Confirmatory Factor Analysis}

A CFA test model analysis indicated that the latent variable is true and may be further processed to validate the structural model.

The first model fit indices are not acceptable since the CFI and TLI are acceptable but the RMSEA is more than the cutoff values on the other hand (Table 4). In the first model, there is not any covariance connection. The final model was produced by using the software's proposed covariance connections (shown in Figure 3). When the final model fit indices are examined, it is observed that the CFI and TLI values are greater than 0.9, the SRMR value is less than 0.08, and the RMSEA value is less than 0.05 (Hair et al., 2014; Yu, 2002). The CFA results indicate that the inventory is at an acceptable level. Table 5 depicts factor loading values. 


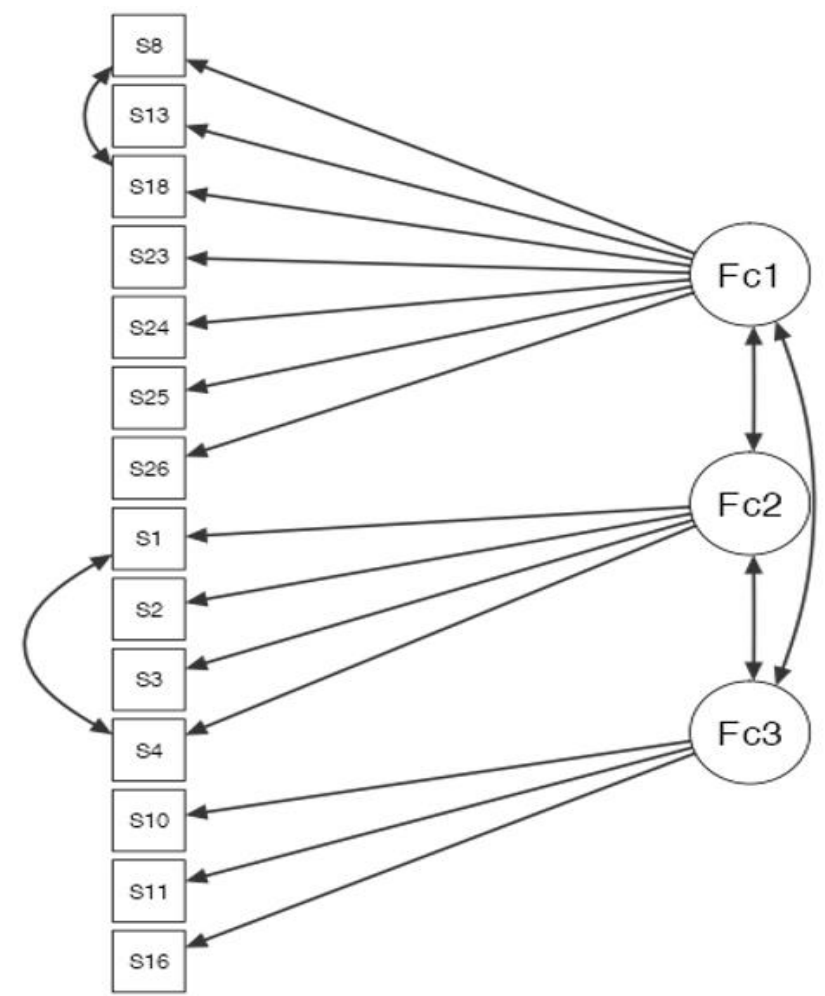

Figure 3. Path diagram of CFA

Table 5. Factor loading values, $Z$, and $p$ values

\begin{tabular}{lcccccc}
\hline Factor & Indicator & Estimate & SE & $\mathrm{Z}$ & $\mathrm{p}$ & Std. Estimate \\
\hline Functional impairment & Item8 & 0.612 & 0.0718 & 8.51 & $<.001$ & 0.574 \\
& Item13 & 0.648 & 0.0712 & 9.10 & $<.001$ & 0.603 \\
& Item18 & 0.598 & 0.0631 & 9.49 & $<.001$ & 0.626 \\
& Item23 & 0.783 & 0.0588 & 13.32 & $<.001$ & 0.801 \\
& Item24 & 0.676 & 0.0611 & 11.07 & $<.001$ & 0.702 \\
& Item25 & 0.706 & 0.0668 & 10.57 & $<.001$ & 0.683 \\
& Item26 & 0.793 & 0.0661 & 12.00 & $<.001$ & 0.746 \\
\hline Anxiety & Item1 & 0.837 & 0.0557 & 15.04 & $<.001$ & 0.890 \\
& Item2 & 0.697 & 0.0533 & 13.07 & $<.001$ & 0.778 \\
& Item3 & 0.653 & 0.0571 & 11.43 & $<.001$ & 0.706 \\
& Item4 & 0.760 & 0.0578 & 13.15 & $<.001$ & 0.823 \\
Compulsive behaviour & Item10 & 0.615 & 0.0615 & 9.99 & $<.001$ & 0.667 \\
& Item11 & 0.738 & 0.0633 & 11.67 & $<.001$ & 0.749 \\
& Item16 & 0.734 & 0.0613 & 11.99 & $<.001$ & 0.767 \\
\hline
\end{tabular}

When the relationship of each item with the relevant factors is examined, it is at the $p<0.001$ level for all items. According to the CFA result, there is no item that should be removed from the inventory.

\section{Reliability Analysis}

Sufficient reliability is defined as being greater than 0.7 for both reliability measurements. According to Taber (2018), a Cronbach alpha of greater than 0.60 is an acceptable threshold. Composite reliability must exceed 0.7 (Hair et al., 2014; Schumacker \& Lomax, 2004). Cronbach's alpha and McDonald's value are both better than 0.7, as seen in Table 6. Additionally, it was revealed that Cronbach's alpha value for the overall scale is 0.904 , whereas McDonald's alpha value is 0.905 . 
Table 6. Reliability results for total inventory and sub-dimension

\begin{tabular}{lccc}
\hline Factors name & Number of items & Cronbach $\alpha$ & McDonald's $\omega$ \\
\hline Functional impairment & 7 & 0.850 & 0.854 \\
Anxiety & 4 & 0.854 & 0.856 \\
Compulsive behavior & 3 & 0.771 & 0.772 \\
Total inventory & 14 & 0.904 & 0.905 \\
\hline
\end{tabular}

\section{DISCUSSION AND CONCLUSIONS}

The purpose of this study is to investigate the psychometric features of the smartphone addiction inventory (SPAI) in the setting of Russia. The study was conducted at Kazan Federal University, The State University of Management, Sechenov University, RUDN-University, Moscow State Regional University, and MGIMO University during the autumn semester of the 2020-2021 academic year.

Exploratory Factor Analysis (EFA) and Confirmatory Factor Analysis (CFA) were used on 209 students to improve the inventory. The EFA method is stated one of the multivariate statistical techniques (Edwards \& Bagozzi, 2000; Watkins, 2018). In EFA Varimax with Kaiser normalization was used as the factor method. Also, in order to determine the number of the factors, the parallel analysis approach was used. In a parallel analysis, real eigenvalues are compared with the random ordered eigenvalues. Factor is kept when actual eigenvalues exceed the random ordered eigenvalues (Williams et al., 2010). The item is also deleted if it (a) loaded on multiple factors with a difference of less than 0.1 between the two loading factors, or (b) obtained a factor load of less than 0.4. (Deng et al., 2017). As a consequence, only 14 things remained following the removal of the items $5,6,7,9,12,14,15,17,19,20,21$, and 22 from the list of possible items.

As a result of second calculation, KMO (0.907) and Bartlett's test $\left(\chi^{2}=1362, \mathrm{df}=91, \mathrm{p}<0.001\right)$ were on the significant level (Yong \& Pearce, 2013). All items were classified into three variables using a scree plot and parallel analysis.

Factor loadings range from +0.497 to +0.759 . There are seven items in the first factor. When the seven items stated above are considered, it becomes evident that the items are linked to a degradation in an individual's quality of life. As a result, the first element might be referred to as "functional impairment." There are four items in the second factor. They are almost always linked to an emotional problem. As a result, it may be referred to as "Anxiety" The majority of their concerns revolve with self-control. "Compulsive behaviour" is a term that has been used to describe it. In another study, the inventory items were grouped in a different way and the factors were named as Time Spent", "Compulsiveness", "Daily Life Interference", "Craving", "Sleep Disorder" (Pavia et al., 2016).

A CFA test model analysis was used to assess when the structure in the inventory is correct and may be further processed to validate the structural model. When looking at the final model fit indices, the CFI and TLI values are both greater than 0.95 , the SRMR value is less than 0.08 , and the RMSEA value is less than 0.05 . (Hair et al., 2014). The scale is in line with the findings of the CFA. CFA calculation was made in the scale development study (Lin et al., 2014). In the study by Pavia et al. (2016), the 5-factor construct was confirmed by CFA. It was also discovered that the total scale of Cronbach alpha value is 0.904, and of McDonald is 0.905. Lin et al. (2014) calculated Cronbach alpha as 0.94

As a result, validity and reliability studies of Smartphone Addiction Inventory in the Russian context were conducted. According to the results of the analysis, a short inventory of 14 items and 3 factors was obtained. It is recommended for future researchers to conduct the validity and reliability study of the inventory with different groups. In addition, comparisons can be made by repeating the study in different cultural contexts. In addition, the inventory can be used to determine the prevalence of smartphone addiction among university students, especially with the widespread use of smartphones due to the pandemic. The study collects data on a voluntary basis. As a result, faculties and departments were not considered. The sample may not be representative of all students. This is a research limitation. 
Author contributions: All authors were involved in concept, design, collection of data, interpretation, writing, and critically revising the article. All authors approve final version of the article.

Funding: This paper has been supported by the Kazan Federal University Strategic Academic Leadership Program.

Declaration of interest: Authors declare no competing interest.

Data availability: Data generated or analysed during this study are available from the authors on request.

\section{REFERENCES}

Agarwal, V., \& Kar, S. K. (2015). Technology addiction in adolescents. Journal of Indian Association for Child and Adolescent Mental Health, 11(3), 170-174.

Akhmadieva, R. S., Mikhaylovsky, M. N., Simonova, M. M., Nizamutdinova, S. M., Prokopyev, A. I., \& Ostanina, S. S. (2021). Public relations in organizations in sportsman students view: Development of management tools or healthy and friendly relations formation. Journal of Human Sport and Exercise, 16(3proc), 1272-1279. https://doi.org/10.14198/jhse.2021.16.Proc3.43

Anstey Watkins, J. O. T., Goudge, J., Gómez-Olivé, F. X., \& Griffiths, F. (2018). Mobile phone use among patients and health workers to enhance primary healthcare: A qualitative study in rural South Africa. Social Science and Medicine, 198, 139-147. https://doi.org/10.1016/j.socscimed.2018.01.011

Arrivillaga, C., Rey, L., \& Extremera, N. (2020). Adolescents' problematic internet and smartphone use is related to suicide ideation: Does emotional intelligence make a difference? Computers in Human Behavior, 110, 106375. https://doi.org/10.1016/j.chb.2020.106375

ASAM. (2019). ASAM definition of addiction. https://www.asam.org/Quality-Science/definition-of-addiction

Awofala, A. O. (2020). Investigating nomophobia as a predictor of smartphone addiction among Nigerian preservice mathematics teachers. Indonesian Journal of Informatics Education, 4(2), 42. https://doi.org/10.20961/ijie.v4i2.40021

Bauer, M., Glenn, T., Geddes, J., Gitlin, M., Grof, P., Kessing, L. V., Monteith, S., Faurholt-Jepsen, M., Severus, E., \& Whybrow, P. C. (2020). Smartphones in mental health: A critical review of background issues, current status and future concerns. International Journal of Bipolar Disorders, 8(1), 1-19. https://doi.org/10.1186/s40345-019-0164-x

Billieux, J., Maurage, P., Lopez-Fernandez, O., Kuss, D. J., \& Griffiths, M. D. (2015). Can disordered mobile phone use be considered a behavioral addiction? An update on current evidence and a comprehensive model for future research. Current Addiction Reports, 2(2), 156-162. https://doi.org/10.1007/s40429015-0054-y

Busch, P. A., \& McCarthy, S. (2021). Antecedents and consequences of problematic smartphone use: A systematic literature review of an emerging research area. Computers in Human Behavior, 114, 106414. https://doi.org/10.1016/j.chb.2020.106414

Cha, S. S., \& Seo, B. K. (2018). Smartphone use and smartphone addiction in middle school students in Korea: Prevalence, social networking service, and game use. Health Psychology Open, 5(1), 1-15. https://doi.org/10.1177/2055102918755046

Chen, J., Liang, Y., Mai, C., Zhong, X., \& Qu, C. (2016). General deficit in inhibitory control of excessive smartphone users: Evidence from an event-related potential study. Frontiers in Psychology, 7, 1-9. https://doi.org/10.3389/fpsyg.2016.00511

Chhabra, R., Verma, S., \& Rama Krishna, C. (2019). Detecting aggressive driving behavior using mobile smartphone. In Proceedings of 2nd International Conference on Communication, Computing and Networking (pp. 513-521). https://doi.org/10.1007/978-981-13-1217-5_49 
Ching, S. M., Yee, A., Ramachandran, V., Lim, S. M. S., Sulaiman, W. A. W., Foo, Y. L., \& Hoo, F. K. (2015). Validation of a Malay version of the smartphone addiction scale among medical students in Malaysia. PLOS ONE, 10(10), 1-11. https://doi.org/10.1371/journal.pone.0139337

Choi, C., Hums, M. A., \& Bum, C. H. (2018). Impact of the family environment on juvenile mental health: eSports online game addiction and delinquency. International Journal of Environmental Research and Public Health, 15(12), 2850. https://doi.org/10.3390/ijerph15122850

Contractor, A. A., Weiss, N. H., Tull, M. T., \& Elhai, J. D. (2017). PTSD's relation with problematic smartphone use: Mediating role of impulsivity. Computers in Human Behavior, 75, 177-183. https://doi.org/10.1016/j.chb.2017.05.018

Deng, M., Wang, S., Guan, W., \& Wang, Y. (2017). The development and initial validation of a questionnaire of inclusive teachers' competency for meeting special educational needs in regular classrooms in China. International Journal of Inclusive Education, 21(4), 416-427. https://doi.org/10.1080/13603116.2016.1197326

De-Sola, J., Talledo, H., Rubio, G., \& de Fonseca, F. R. (2017). Development of a mobile phone addiction craving scale and its validation in a Spanish adult population. Frontiers in Psychiatry, 8, 90. https://doi.org/10.3389/fpsyt.2017.00090

Edwards, J. R., \& Bagozzi, R. P. (2000). On the nature and direction of relationships between constructs and measures. Psychological Methods, 5(2), 155-174. https://doi.org/10.1037//1082-989x.5.2.155

Elhai, J. D., Dvorak, R. D., Levine, J. C., \& Hall, B. J. (2017). Problematic smartphone use: A conceptual overview and systematic review of relations with anxiety and depression psychopathology. Journal of Affective Disorders, 207, 251-259. https://doi.org/10.1016/j.jad.2016.08.030

Felisoni, D. D., \& Godoi, A. S. (2018). Cell phone usage and academic performance: An experiment. Computers and Education, 117, 175-187. https://doi.org/10.1016/j.compedu.2017.10.006

Fjeldsoe, B. S., Marshall, A. L., \& Miller, Y. D. (2009). Behavior change interventions delivered by mobile telephone short-message service. American Journal of Preventive Medicine, 36(2), 165-173. https://doi.org/10.1016/j.amepre.2008.09.040

Fraenkel, J. R., Wallen, N. E., \& Hyun, H. H. (2012). How to design and evaluate research in education. McGraw-Hill.

Griffiths, M. (2005). A "components" model of addiction within a biopsychosocial framework. Journal of Substance Use, 10(4), 191-197. https://doi.org/10.1080/14659890500114359

Gutiérrez, J. D. S., de Fonseca, F. R., \& Rubio, G. (2016). Cell-phone addiction: A review. Frontiers in Psychiatry, 7, 175. https://doi.org/10.3389/fpsyt.2016.00175

Hair, J. F. J., Black, W. C., Babin, B. J., \& Anderson, R. E. (2014). Multivariate data analysis (7th ed.). Pearson Education, Inc.

Harris, B., Regan, T., Schueler, J., \& Fields, S. A. (2020). Problematic mobile phone and smartphone use scales: A systematic review. Frontiers in Psychology, 11, 672. https://doi.org/10.3389/fpsyg.2020.00672

Hayton, J. C., Allen, D. G., \& Scarpello, V. (2004). Factor retention decisions in exploratory factor analysis: A tutorial on parallel analysis. Organizational Research Methods, 7(2), 191-205. https://doi.org/10.1177/1094428104263675

Horvath, J., Mundinger, C., Schmitgen, M. M., Wolf, N. D., Sambataro, F., Hirjak, D., Kubera, K. M., Koenig, J., $\&$ Wolf, R. C. (2020). Structural and functional correlates of smartphone addiction. Addictive Behaviors, 105, 1-7. https://doi.org/10.1016/j.addbeh.2020.106334 
Huckins, J. F., da Silva, A. W., Wang, W., Hedlund, E., Rogers, C., Nepal, S. K., Wu, J., Obuchi, M., Murphy, E. I., Meyer, M. L., Wagner, D. D., Holtzheimer, P. E., \& Campbell, A. T. (2020). Mental health and behavior of college students during the early phases of the COVID-19 pandemic: Longitudinal smartphone and ecological momentary assessment study. Journal of Medical Internet Research, 22(6), e20185. https://doi.org/10.2196/20185

Jackson, D. L., Gillaspy, J. A., \& Purc-Stephenson, R. (2009). Reporting practices in confirmatory factor analysis: An overview and some recommendations. Psychological Methods, 14(1), 6-23. https://doi.org/10.1037/a0014694

Kline, T. J. B. (2005). Psychological testing: A practical approach to design and evaluation. SAGE. https://doi.org/10.4135/9781483385693

Lepp, A., Barkley, J. E., \& Karpinski, A. C. (2014). The relationship between cell phone use, academic performance, anxiety, and satisfaction with life in college students. Computers in Human Behavior, 31(1), 343-350. https://doi.org/10.1016/j.chb.2013.10.049

Lin, Y. H., Chang, L. R., Lee, Y. H., Tseng, H. W., Kuo, T. B. J., \& Chen, S. H. (2014). Development and validation of the smartphone addiction inventory (SPAI). PLOS ONE, 9(6), e98312. https://doi.org/10.1371/journal.pone.0098312

Lopez-Fernandez, O. (2017). Short version of the smartphone addiction scale adapted to Spanish and French: Towards a cross-cultural research in problematic mobile phone use. Addictive Behaviors, 64, 275-280. https://doi.org/10.1016/j.addbeh.2015.11.013

Marcolino, M. S., Oliveira, J. A. Q., D’Agostino, M., Ribeiro, A. L., Alkmim, M. B. M., \& Novillo-Ortiz, D. (2018). The impact of mhealth interventions: Systematic review of systematic reviews. JMIR MHealth and UHealth, 6(1), e23. https://doi.org/10.2196/mhealth.8873

Mikhaylovsky, M. N., Lopatkova, I. V., Komarova, N. M., Rueva, E. O., Tereschuk, K. S., \& Emelyanenkova, A. V. (2019). Cyberbulling as a new form of a threat: A physiological, psychological and medicinal aspects. Electronic Journal of General Medicine, 16(6), em161. https://doi.org/10.29333/ejgm/114268

Mitchell, L., \& Hussain, Z. (2018). Predictors of problematic smartphone use: An examination of the integrative pathways model and the role of age, gender, impulsiveness, excessive reassurance seeking, extraversion, and depression. Behavioral Sciences, 8(8), 74. https://doi.org/10.3390/bs8080074

O'Dea, S. (2021). Number of smartphone users from 2016 to 2021. https://www.statista.com/statistics/ 330695/number-of-smartphone-users-worldwide/

Oviedo-Trespalacios, O., King, M., Haque, M. M., \& Washington, S. (2017). Risk factors of mobile phone use while driving in Queensland: Prevalence, attitudes, crash risk perception, and task-management strategies. PLoS ONE, 12(9), e0183361. https://doi.org/10.1371/journal.pone.0183361

Pavia, L., Cavani, P., Di Blasi, M., \& Giordano, C. (2016). Smartphone addiction inventory (SPAI): Psychometric properties and confirmatory factor analysis. Computers in Human Behavior, 63, 170-178. https://doi.org/10.1016/j.chb.2016.05.039

Rezaee, F., \& Pedret, A. (2018). A critical review of Silicon Valley solutions for smartphone addiction. Ideology, 3(3), 189-196. http://digitaldetox.org

Roberts, J. A., Pullig, C., \& Manolis, C. (2015). I need my smartphone: A hierarchical model of personality and cell-phone addiction. Personality and Individual Differences, 79, 13-19. https://doi.org/10.1016/j.paid.2015.01.049

Schumacker, R. E., \& Lomax, R. G. (2004). A beginner's guide to structural equation modeling (2nd Ed.). Lawrence Erlbaum Associates, Inc. https://doi.org/10.4324/9781410610904 
Stanislaus, S., Vinberg, M., Melbye, S., Frost, M., Busk, J., Bardram, J. E., Kessing, L. V., \& Faurholt-Jepsen, M. (2020). Smartphone-based activity measurements in patients with newly diagnosed bipolar disorder, unaffected relatives and control individuals. International Journal of Bipolar Disorders, 8(1), 32. https://doi.org/10.1186/s40345-020-00195-0

Taber, K. S. (2018). The use of Cronbach's alpha when developing and reporting research instruments in science education. Research in Science Education, 48(6), 1273-1296. https://doi.org/10.1007/s11165016-9602-2

The Jamovi Project. (2021). Jamovi ((Version 1.6)). https://www.jamovi.org/

Thomée, S., Härenstam, A., \& Hagberg, M. (2011). Mobile phone use and stress, sleep disturbances, and symptoms of depression among young adults - A prospective cohort study. BMC Public Health, 11, 66. https://doi.org/10.1186/1471-2458-11-66

Vezzoli, M., Colombo, A., Marano, A., Zoccatelli, G., \& Zogmaister, C. (2021). Test for mobile phone dependence: Psychometric properties and confirmatory factor analysis. Current Psychology. https://doi.org/10.1007/s12144-021-01449-5

Watkins, M. W. (2018). Exploratory factor analysis: A guide to best practice. Journal of Black Psychology, 44(3), 219-246. https://doi.org/10.1177/0095798418771807

Williams, B., Onsman, A., \& Brown, T. (2010). Exploratory factor analysis: A five-step guide for novices. Journal of Emergency Primary Health Care, 8(3), 1-13. https://doi.org/10.33151/ajp.8.3.93

Yates, A. (1987). Multivariate exploratory data analysis: A perspective on exploratory factor analysis. State University of New York Press. https://doi.org/10.2307/1269132

Yong, A. G., \& Pearce, S. (2013). A beginner's guide to factor analysis: Focusing on exploratory factor analysis. Tutorials in Quantitative Methods for Psychology, 9(2), 79-94. https://doi.org/10.20982/ tqmp.09.2.p079

Young, K. (2009). Internet addiction: Diagnosis and treatment considerations. Journal of Contemporary Psychotherapy, 39(4), 241-246. https://doi.org/10.1007/s10879-009-9120-x

Yu, C.-Y. (2002). Evaluating cutoff criteria of model fit indices for latent variable models with binary and continuous outcomes [PhD thesis, University of California]. http://repositorio.utn.edu.ec/bitstream/ 123456789/1207/3/PG 175_Capitulo II.pdf

Correspondence: Almira R. Bayanova, Kazan (Volga Region) Federal University, Kazan, Russia. E-mail: almira-djl@mail.ru 


\section{APPENDIX 1}

\section{Items of Smartphone Addiction Inventory (English)}

1. I was told more than once that I spent too much time on smartphone.

2. I feel uneasy once I stop smartphone for a certain period of time.

3. I find that I have been hooking on smartphone longer and longer.

4. I feel restless and irritable when the smartphone is unavailable.

5. I feel very vigorous upon smartphone use regardless of the fatigues experienced.

6. I use smartphone for a longer period of time and spend more money than I had intended.

7. Although using smartphone has brought negative effects on my interpersonal relationships, the amount of time spent on Internet remains unreduced.

8. I have slept less than $4 \mathrm{~h}$ due to using smartphone more than once.

9. I have increased substantial amount of time using smartphone per week in recent 3 months.

10.I feel distressed or down once I cease using smartphone for a certain period of time.

11.I fail to control the impulse to use smartphone.

12.I find myself indulged on the smartphone at the cost of hanging out with friends.

13.I feel aches and soreness in the back or eye discomforts due to excessive smartphone use.

14. The idea of using smartphone comes as the first thought on mind when wake up each morning.

15.To use smartphone has exercised certain negative effects on my schoolwork or job performance.

16.I feel missing something after stopping smartphone for a certain period of time.

17.My interaction with family members is decreased on account of smartphone use.

18. My recreational activities are reduced due to smartphone use.

19.I feel the urge to use my smartphone again right after I stopped using it.

20.My life would be joyless hadn't there been smartphone.

21.Surfing the smartphone has exercised negative effects on my physical health. For example, viewing smartphone when crossing the street; fumbling with one's smartphone while driving or waiting, and resulted in danger.

22.I try to spend less time on smartphone, but the efforts were in vain.

23.I make it a habit to use smartphone and the sleep quality and total sleep time decreased.

24.I need to spend an increasing amount of time on smartphone to achieve same satisfaction as before.

25.I cannot have meal without smartphone use.

26.I feel tired on daytime due to late-night use of smartphone. 